\title{
Structural and Mechanical Design of Solar Tracking System
}

\author{
D. Billy, J. Paulmar Pushparaj, M. Vetrivel Sezhian, S. Arulvel, U. Omshakthivel
}

\begin{abstract}
This project deals with the PV Panel arrangement and its moving technique, auto tracking elements and its design. Domestic and commercial sectors are using battery backup system to challenge the power cut. Power demand is drastically increasing unproportionally to the supply. Hence, tapping of electricity from sun is mandatory requirement. A set of $P V$ modules are integrated to the battery backup system. The charge mode selector will assign priority to use solar energy for battery charging / usage. In this system, the sunny days are used to tap out the energy. The efficiency of the PV cells are small only but by using auto tracking system the maximum possible energy can be tapped.

Worm gear configurations in which the gear can not drive the worm are said to be self-locking.In this tracking arrangement,the worm gear riveted with PV array tracks the solar radiation.
\end{abstract}

Keywords: Solar tracker, worm gear, structural design, mechanical design.

\section{INTRODUCTION}

Conventional energy resources cause environmental pollutions like Sulphur dioxide (SO2), Nitrous oxide (NOX) and Carbon oxides ( $\mathrm{CO}, \mathrm{CO} 2)$ emissions from boilers and furnaces, Chloro-Fluro carbons (CFC) emissions from refrigerants use, etc. Toxic gases and VOC are released from industrial sector and it affects the environment wheres renewable energy resources are free from pollution. So, it will be better to go for renewable energies. Energy can be classified as renewable and non renewable. Renewable energy resources includes solar,wind,geothermal,biomass, hydropower etc. Nuclear, fossil fuels etc are the sources of non renewable energy. Renewable energy sources like solar does not have any limitations when compared to another renewable energy sources. Research shows that more than $50 \%$ of the total energy will be consumed only from solar energy by 2050.Adding solar energy to the conventional thermal power plants, we can increase the efficiency of the plant by $30 \%$. This technology has scope for the replacement of all conventional energy sources that we are using today.

\section{Types Of Mechanical Arrangements Used In Solar Panels}

I. The first mechanical arrangement of the solar tracker comprises of structural link members,turn table mechanism and straight bevel gearing mechanism.In this mechanical arrangements, a straight bevel gearing is used

Revised Manuscript Received on 14 August, 2019.

Mr. Billy D, Mechanical Engineering, Easwari Engineering College, Chennai, Tamilnadu, India. (Email: simonbilly3@gmail.com)

Mr. Paulmarpushparaj.J, Mechanical Engineering,Easwari Engineering College, Chennai,Tamilnadu, India (Email:paulmarsamuel@gmail.com)

Mr. M.VetrivelSezhian, Mechanical Engineering,Easwari Engineering College, Chennai,Tamilnadu, India. (Email: hod.mech@eec.srmrmp.edu.in)

Mr. S. Arulvel,

Mr. U. Omshakthivel for accuracy but the material cost of the system is high because of many link members are used to carry wind load.

II. The second mechanical arrangement of the solar tracker depends on the number of columns to withstand the dead load and live load.One or two columns may be used for the solar tracking system. Single column used in the structure is not stable and rigid due to wind load.

III. The third mechanical arrangement of the solar tracker is the two columns used in the structure that gives high stability and resistant to wind load.Also actuator and braking systems are included in the structure which increases dead load and also cost.

\section{METHODOLOGY}

The objective of this project is to analyse the various the various solar tracking systems such as closed loop tracking system,manual tracking system,and automatic tracking systems.A suitable gear was designed to perform selflocking and auto tracking for PV panel.Cost calculation was done to show the reduction in cost,with the usage of worm gear and channel section.

The following methodology is adopted for structural and mechanical design of solar tracker,

Step 1 : Mechanical Design of Solar Tracker

Step 2: Selection of Motor

Step 3: Tracking Resolution of Solar Tracker

Step 4: Structural Design of Solar Tracker.

\section{RESULT AND DISCUSSION}

STEP 1: Computation of input load

Considering upward load and downward load acting on the bottom and top half of the panel subjected to maximum moment. For maximum upward load, (considering bottom half of the panel)

Maximum moment due to upward load $\left(\mathrm{Mt}_{1}\right)=\left(\mathrm{wL}^{2}\right) / 2$ is calculated to be $842.415 \mathrm{kgfm}$. Similarly, maximum downward load, (considering top half of the panel) is calculated to be $887.5 \mathrm{kgf}$. Total moment on worm gear is found to be $4512.139 \mathrm{kgfm}$.

STEP-2: Computation of axial module:

Axial module is calculated by $\mathrm{m}_{\mathrm{t}}=1.24\left(\mathrm{M}_{\mathrm{t}}\right)^{0.33} /(\mathrm{Zqy \sigma})^{0.33}$. and the result was found,

STEP-3: Self-locking design:

The self-locking design of worm gear plays an important role in locking the PV array instead of other braking systems like actuator braking,hydraulic braking systems etc. The self loacking design of worm gear plays an important role in locking the PV array instead of other braking systems like

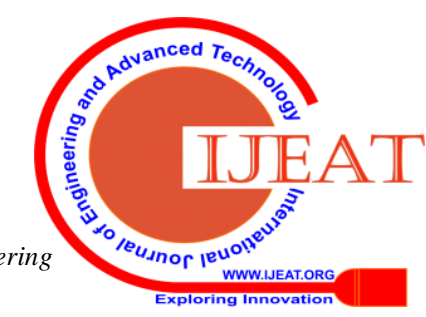


actuatorbraking,hydraulic braking systems etc.From the equation $\quad \tan \Upsilon=\mathrm{z} 1 / \mathrm{q}$ laed angle is found to be $5.1^{\circ}$ On considering Conditions for self-locking It is found between 5 to 6 degrees

1. $\Upsilon$ should be

2.Efficiency of worm drive should be 50 percent and by taking $\eta=\tan \Upsilon /$ $\tan (\Upsilon+\ell)$ and $\mu=\tan \ell$

Frictional coefficient was identified $\mu=0.0892$

.STEP-4: Computation of worm rpm (revolutions per minute)

$$
\mathrm{V}_{\mathrm{s}}=\mathrm{mx} \mathrm{n} / 1910\left\{\operatorname{sqrt}\left(\mathrm{z} 1^{2}+\mathrm{q}^{2}\right)\right\}
$$

From the above equation we get $n=5.23 \mathrm{rpm}$, for taken velocity.

STEP-5: Computation of worm and wheel dimensions

Worm wheel parameters are taken as

Bottom clearence, $\mathrm{c}=0.25 \mathrm{~m}_{\mathrm{x}}$, Tip diameter, da1 = $\mathrm{d} 1+2 * \mathrm{~m}_{\mathrm{x}}$

Root diameter, df1 $=\mathrm{d} 1-2 * \mathrm{~m}_{\mathrm{x}}-2 \mathrm{c}$, Pitch diameter, $\mathrm{d} 1^{\prime}=$ $\mathrm{m}_{\mathrm{x}} *(\mathrm{q}+2 \mathrm{x})$. Worm wheel throat parameters are taken as,

Throat tip radius, $\mathrm{R} 1=\mathrm{d} 1 / 2-\mathrm{mx}$ Throat root radius, $\mathrm{R} 2=$ $\mathrm{d} 1 / 2+\mathrm{m}_{\mathrm{x}}+\mathrm{c}$, Tip relief radius, $\mathrm{r} 1=0.1 \mathrm{mx}$, Root relief radius, $\mathrm{r} 2=0.2 \mathrm{mx}$, Nominal tooth thickness on reference diameter in axial section, $\mathrm{S}=3.14 * \mathrm{~m}_{\mathrm{x}} / 2$, Nominal tooth thickness on reference diameter in normal section , $\mathrm{Sn}=\left(3.14 * \mathrm{~m}_{\mathrm{x}} * \cos (\Upsilon)\right) / 2$, Axial pitch, $\mathrm{px}=3.14 * \mathrm{~m}_{\mathrm{x}}$. Lead,

$\mathrm{pz}=\mathrm{z} 1 * \mathrm{px}$, Face width of wheel, $\mathrm{b}=0.75 \mathrm{~d} 1$, Length of the worm, $\mathrm{L}=(11+0.06 \mathrm{z} 1) * \mathrm{~m}_{\mathrm{x}}$.

STEP- 6 : Computation of servo power

Servo power computation was done for proper selection of motor. Power of worm can be calculated as,

$\mathrm{P}=(2 * 3.14 * \mathrm{~N} * \mathrm{~T} * 0.736) /(4500 * \eta) \quad$.From this equation power of worm can be found out to be $0.484 \mathrm{KW}$

Power of worm for different rpm is calculated and the power of worm selected is $10 \%$ lesser than the total power production from the system. Therefore,

Power of motor $=$ (power of worm) $/(\eta$ worm to gear box $* \eta$ gear box $* \eta$ motor)

$\mathrm{P}($ watts $)=(2 * 3.14 * \mathrm{~N} * \mathrm{~T} * 736) /(4500)$

Once the power is attained, by varying the rpm we get the suitable torque. Hence the characteristic curve of torque vs rpm is plotted.

\section{Torque Vs Speed Characteristic Curve}

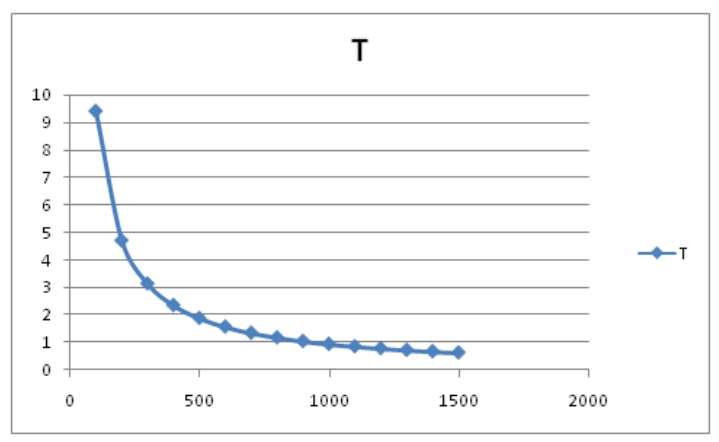

Torque vs Speed characteristic curve

\section{Motor Specification}

Motor is selected based on the characteristic curve and the specification of motor found out is given below,

1. RATED TORQUE $=0.626 \mathrm{kgfm}$

\section{RATED RPM $=1500 \mathrm{rpm}$}

3. VOLTAGE $=12$ Volt D.C

4. RATED POWER $=1 \mathrm{KW}$ MOTOR.

Tracking Resolution:

Gear ratio of wheel $=110$

360 degree of wheel revolution $=110$ revolution of worm

5 degree wheel rotation is considered.

$($ One pulse, Rw/pulse $)=1.527 \mathrm{rev} /$ pulse

Total pulse per day $=140 / 5$

Total pulse per day $=28$

Consider tracking time varies from 0 to 30 seconds

Tracking rpm of worm needed to the desired tracking time(t) $. N=R w / t$. As varying the tracking time, the required rpm of worm is attained and the suitable tracking time is selected.

Tracking time $=18$ seconds.

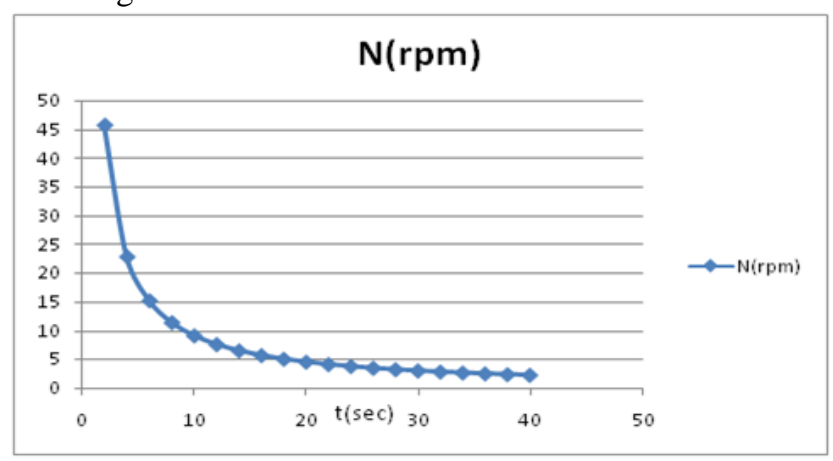

Speed vsTracking time

Total power needed for worm $(\mathrm{KW})=(28 * 2 *$ tracking time $(\mathrm{t})) /(3600)$

Total power needed for tracking $=0.28 \mathrm{KWhr}$

Total power produced per day $=9.33 \mathrm{KWhr}$

Power produced by the tracker $=1 \mathrm{KW}$

$\%$ of power consumed from power produced $=3 \%$

\section{Structural Design Of Solar Tracker}

\section{Wind speed estimation: IS 875 (Part - 3) is referred}

Wind speed estimation is very important in the design of structural members to withstand the wind load in the desired location. The structural member is designed for the worst case cyclonic conditions.

Computation of wind load on individual structure is essential to estimate the force. The wind load F acting in a direction normal to the individual structure element.

$\mathrm{F}=\mathrm{Cp} * \mathrm{~A} * \mathrm{P}_{\mathbf{z}}$

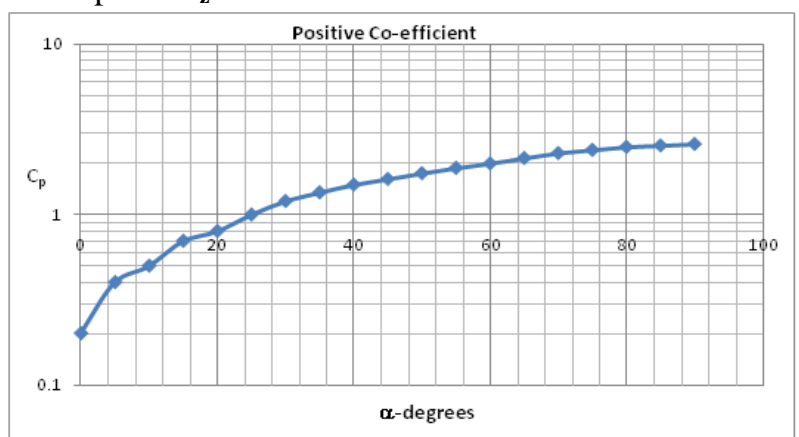

Positive coefficient vs Roof angle

Published By:

Blue Eyes Intelligence Engineering

\& Sciences Publication 


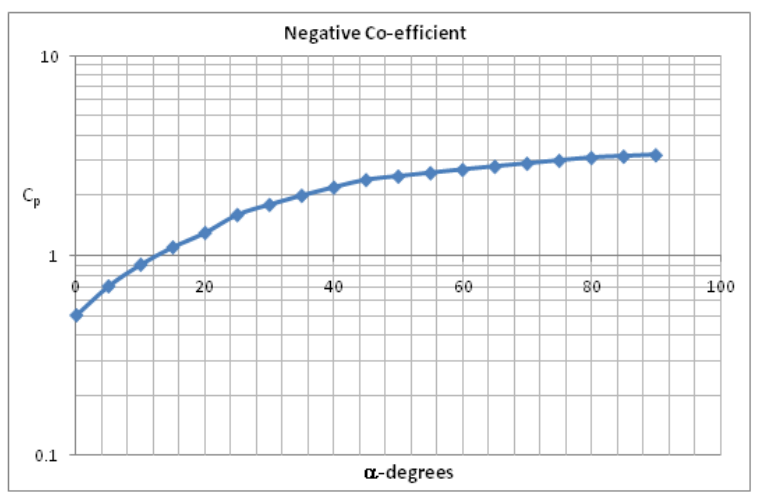

Negative coefficient vs Roof angle

This project solar tracking is designed from $\alpha=+70^{\circ}$ to $\alpha=-70^{\circ}$. Positive $C_{\mathbf{P}}$ and Negative $\mathrm{C}_{\mathbf{P}}$ are referred from the graph fig-1 and fig-2. At $\alpha=70^{\circ}$ maximum $C_{\mathbf{P}}$ is noted hence, this position is considered for maximum wind load assessment on the panel.

$\mathrm{F}=\mathrm{C}_{\mathbf{P}} \mathrm{A} \mathrm{P}_{\mathbf{z}}$

Case (i) Maximum downward load is calculated as

$$
\mathrm{F}=1775 \mathrm{Kg}-\mathrm{f} \quad \mathrm{C}_{\mathrm{p}}=+2.2 \quad \text { from fig-1 }
$$

Case (ii) Maximum upward load

$$
\mathrm{F}=2260 \mathrm{Kg}-\mathrm{f} \quad \mathrm{C}_{\mathbf{p}}=2.8 \quad \text { from fig-2 }
$$

\section{Structural design:-}

$1 \mathrm{KW}$ solar project six solar panels are needed. Each solar panel are sized equally to $1 * \mathrm{~b} * \mathrm{t}$ as $1650 \mathrm{~mm} * 994 \mathrm{~mm} * 48$ $\mathrm{mm}$. All the six panels are arranged as a single rectangular panel by framing inside ' $C$ ' channels. The panel holding arrangements are shown in fig-3.The main frames of the panel holder are made out of stainless steel sheets in the form of channels.

B

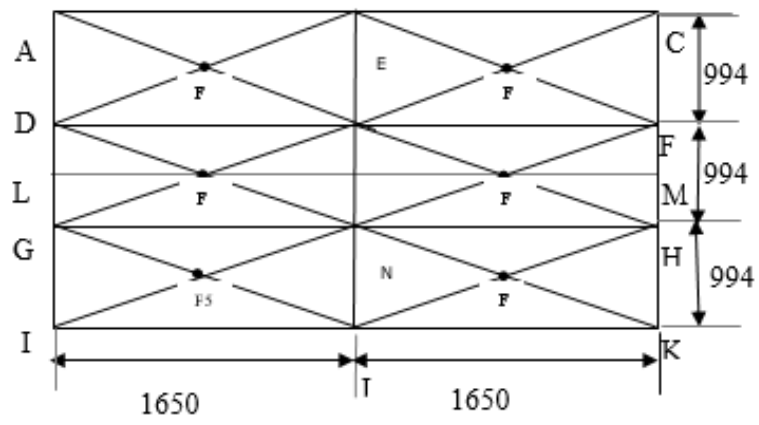

Structure Arrangements :

i. Member $\mathrm{AC}, \mathrm{IK}, \mathrm{AI}, \mathrm{CK}$ are $\mathrm{C}$ type.

ii. Member DE, EF, GN, NH, BE, EN

NJ are double "C" spot welded to form 'I' section.

iii. All joints and corner joints are stitch welded after theinsertion of solar panel.

\section{Design of structural member :}

Each and every element of the structure is considered as load bearing structure. Among them it is grouped as,

(a).The longitudinal elements DE, EF, GN, NH are similar and critical.

(b). The lateral member BJ are connected to the wheel of the gearing mechanism, which is the final member self locks the total load are also critical.

(c).The lateral elements $\mathrm{CK}$ and AI are critical as it only holds the total panel structure in pin for swinging.

\section{Load on structure :}

The panels are having higher area when compared to the structure. The overall area of the panel has to bear the wind load.

$$
\mathrm{F}=\mathrm{A}_{\mathbf{P}} * \mathrm{P}_{\mathbf{Z}} * \mathrm{C}_{\mathbf{P}}
$$

The maximum load $=2260 \mathrm{Kg} \mathrm{f}$

In the structural arrangement, it is seen that the solar panels edges are encapsulated either in the Isection or in the C section.

Hence, The total local bearing length of the structure

$=\mathrm{AB}+\mathrm{BC}+\mathrm{CF}+\mathrm{FH}+\mathrm{HK}+\mathrm{KJ}+\mathrm{JI}+\mathrm{IG}+\mathrm{GD}+\mathrm{DA}+2$ $(\mathrm{BE}+\mathrm{EN}+\mathrm{NJ}+\mathrm{GN}+\mathrm{NH})$ is found to be $22.146 \mathrm{M}$.

UDL on structure is $102 \mathrm{Kg} / \mathrm{m}$

\section{Bending Stress Analysis:}

The bending stress analysis are carried out the analyse the deflection of the structure and the bending stress is withih the safe limit.

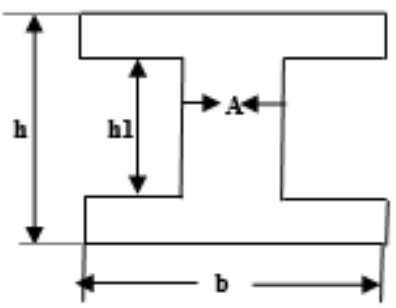

Case (i)

Member DE, EF, GN, NH. This is an I section made out of integrating $\mathrm{C}$ channel two members by stitch TIG spot welding. $\quad \mathrm{DE}$ is taken as an example of the above similar members DE, EF, GN \&NH.Member DE is resting on the member by point $\mathrm{D}$ on $\mathrm{AG}$ and $\mathrm{E}$ on $\mathrm{BN}$. AG and $\mathrm{BN}$ is considered as rigid to analysis the stress on $\mathrm{DE}$.

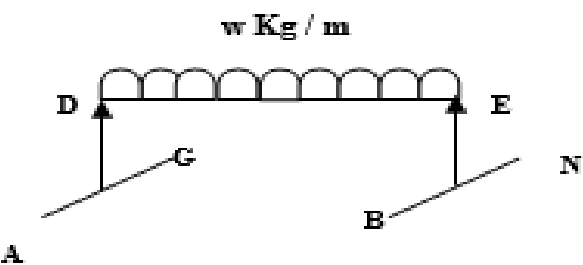

The bending moment can be calculated from the equation given below,

$$
M_{b}=\frac{W l}{8}=(102.05) *\left(\frac{1}{8}\right) *(2 * 1.65) *(1650) \frac{\mathrm{Kg}}{\mathrm{mm}}
$$

Bending stress can be calculated from below equation,

$$
\begin{aligned}
& \text { Moment of Inertia }=\frac{1}{12}\left(b h^{3}+(t-b) * h_{1}^{3}\right) \\
& \text { Section modulus }=\frac{\text { Moment of inertia }}{\left(\frac{h}{2}\right)} \\
& \text { Bending stress } \mathrm{I}_{\mathbf{b}} \quad=\quad \frac{M b}{\text { Section Modulus }}
\end{aligned}
$$


STRUCTURAL AND MECHANICAL DESIGN OF SOLAR TRACKING SYSTEM

\section{Bending stress estimation}

Bending stress is found out from the tabular column given below,

\begin{tabular}{|l|l|l|l|l|l|}
\hline S1.No. & $\mathrm{b}$ & $\mathrm{h}$ & $\mathrm{h} 1$ & $\mathrm{t}$ & $\begin{array}{l}\text { Ib Kg / } \\
\mathrm{mm}^{2}\end{array}$ \\
\hline 1 & 50 & 60 & 50 & 10 & 4.30 \\
\hline 2 & 50 & 58 & 50 & 8 & 5.54 \\
\hline 3 & 50 & 56 & 50 & 6 & 7.62 \\
\hline
\end{tabular}

Case (ii):

Member BE, EN, NJ

This case is also similar to case (i), EN is considered as example the load diagram as shown,

w

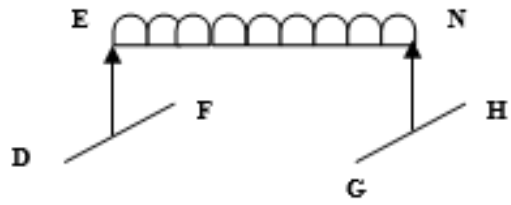

\begin{tabular}{|l|l|l|l|l|l|l|}
\hline S1.No & $\mathrm{b}$ & $\mathrm{h}$ & $\mathrm{h} 1$ & $\mathrm{~A}$ & $\begin{array}{l}\text { Section } \\
\text { Modulus }\end{array}$ & эb \\
\hline 1 & 50 & 60 & 50 & 10 & 16111 & 1.57 \\
\hline 2 & 50 & 58 & 50 & 8 & 125.5 & 2.02 \\
\hline 3 & 50 & 56 & 50 & 6 & 9113 & 2.78 \\
\hline
\end{tabular}

\section{Bending stress analysis}

Case (iii): Member AB, BC, IJ, JK are similar. These members are made out of stainless steel in $\mathrm{C}$ channel.

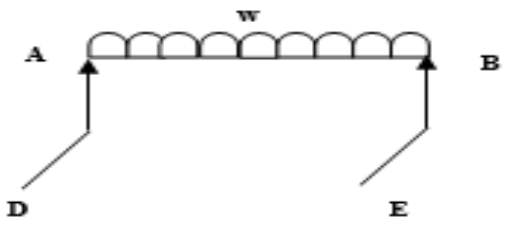

Bending stress for $\mathbf{C}$ section

The loading diagram is shown in fig4.13. A sample member $\mathrm{AB}$ is considered for analysis.

\begin{tabular}{|l|l|l|l|l|l|l|}
\hline S1Non & $\mathrm{b}$ & $\mathrm{h}$ & $\mathrm{h} 1$ & $\mathrm{~A}$ & $\begin{array}{l}\text { Section } \\
\text { Modulus }\end{array}$ & $\mathrm{b} \mathrm{Kg} / \mathrm{mm}^{2}$ \\
\hline 1 & 25 & 60 & 50 & 5 & 6.320 & 5.49 \\
\hline 2 & 25 & 58 & 50 & 4 & 5.040 & 6.89 \\
\hline 3 & 25 & 56 & 50 & 3 & 3.760 & 9.23 \\
\hline
\end{tabular}

\section{Bending stress for $C$ section}

Case (IV): Member AD, DG, GI, CF, FH \& HK are similar. These members are made out of stainless steel in $\mathrm{C}$ channel. Similar analysis carried out as per case (iii) and the following table is generated. The load diagram is shown in fig -10 by considering $\mathrm{FH}$ as sample

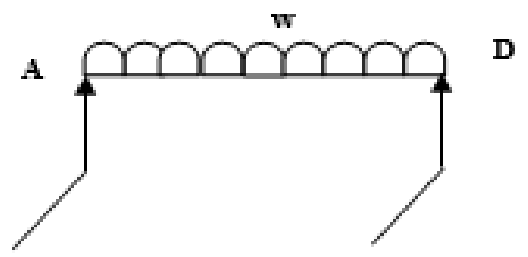

\begin{tabular}{|l|l|l|l|l|l|}
\hline S1.No. & $\mathrm{b}$ & $\mathrm{h}$ & $\mathrm{h} 1$ & $\mathrm{t}$ & $\mathfrak{\Im} \mathrm{b} \mathrm{Kg} / \mathrm{mm}^{2}$ \\
\hline 1 & 25 & 60 & 50 & & 1.99 \\
\hline 2 & 25 & 58 & 50 & & 2.5 \\
\hline 3 & 25 & 56 & 50 & & 3.35 \\
\hline
\end{tabular}

Shear Stress Analysis:

$\mathrm{C}$ type channel is selected to make the total PV panel holding structure. The sheer stress is maximum in the PV panel holding area. The shear stress in all the flat edges of the channels is same. A sample unit length of $\mathrm{C}$ channel is considered for analysis as shown in fig.

The shear area for unit length $=\quad(3.14 / 4) \mathrm{d}^{2}$ $\mathrm{mm}^{2}$.

Load on channel for unit length $=\quad 102.05 \mathrm{Kg} / \mathrm{m}$.

Shear stress

Load / area

$<0.1 \mathrm{Kg} / \mathrm{mm}^{2}$

There is no concern about the shear stress.

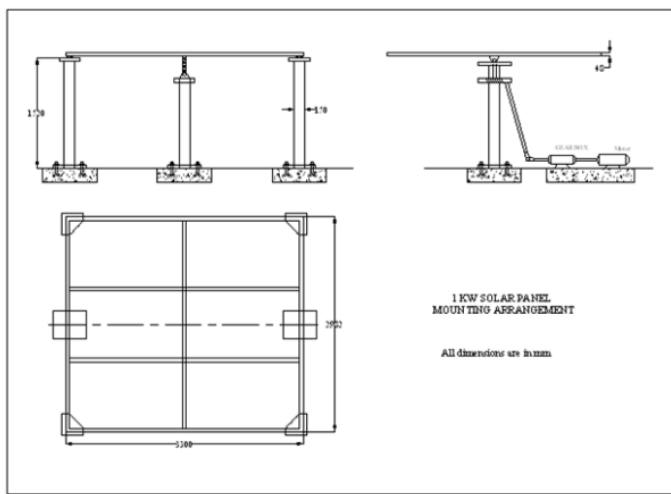

\section{Design Of Holding Mechanism}

Holding Pin

Allowable shear stress fs $=5 \mathrm{Kg} / \mathrm{mm}^{2}$

Shear stress for hardened steel is $20 \mathrm{Kg} / \mathrm{mm}^{2}$ as per IS 1570 40Cr 2Al1M018

By substituting the values, the pin diameter d $=17 \mathrm{~mm} \Phi$

Bending stress

The diameter of pin was calculated as $35 \mathrm{~mm}$ approximately

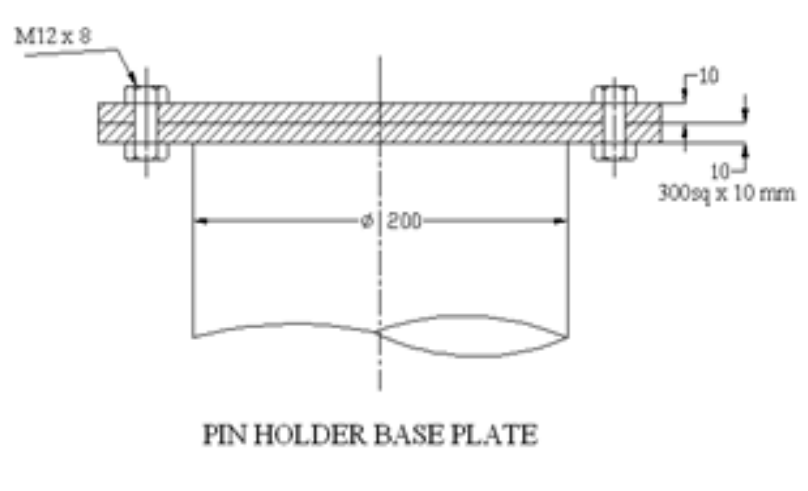




\section{Selection of bearing :}

Bearing is selected from the design data book IS 35RD $30 \mathrm{~K}$ is selected. It is capable of carrying a static load of $2600 \mathrm{Kg}-\mathrm{f}$.

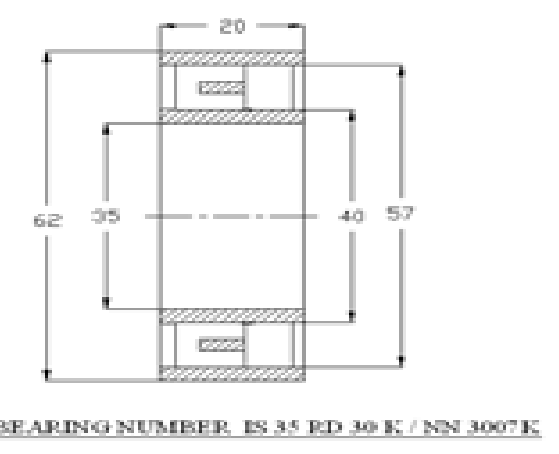

Pin holder design:

Load on the pin holder $=1130 \mathrm{Kg}-\mathrm{f}$
Load on the pin holder $=1130 \mathrm{kgf}$
$\mathrm{b}=90 \mathrm{~mm}$ and $\mathrm{h}=100 \mathrm{~mm}$
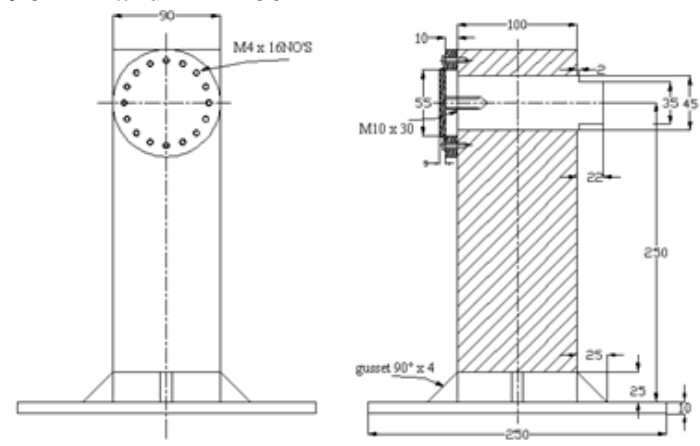

PIN HOLDER

$\mathrm{fb} \quad=2.06 \mathrm{kgf} / \mathrm{mm} 2$

$\mathrm{Mb}=1130 \times 250$

$=282500 \mathrm{kgf}-\mathrm{mm}$

\section{Bearing holder design}

$\mathrm{L}=1130 \mathrm{~kg}-\mathrm{f}$

Bearing outer race $62 \mathrm{~mm} \Phi$ is housed inside a collar of $10 \mathrm{~mm}$ thick made as a single piece with the base dimension plate as $90 \mathrm{~mm} \times 120 \mathrm{~mm} \times 10 \mathrm{~mm}$ as shown in figure.

fs on bearing holder

$\mathrm{d}=72 \mathrm{~mm}$

$=0.277 \mathrm{~kg} / \mathrm{mm} 2$ which is allowable shear stress
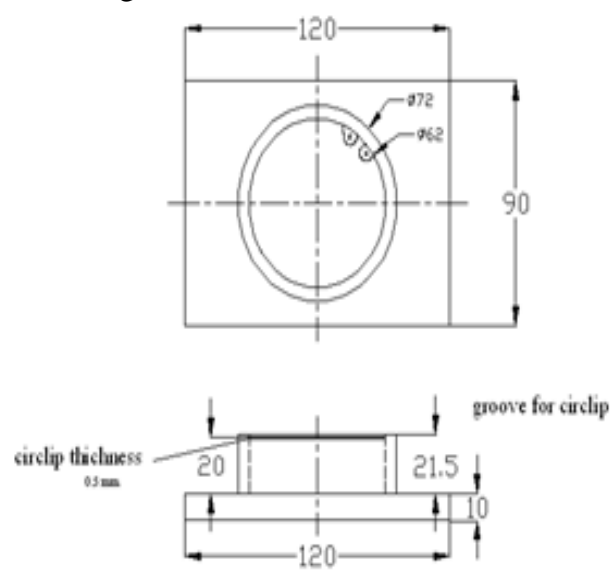

BEARING HOLDER

\section{Column design:}

The column design is important in any structural design to carry the dead load of the structures.It is designed and analysed by Euler's crippling formula.

Euler's formula for crippling load or buckling load is given by,

$\mathrm{Wcr}=\left(\mathrm{C}^{*} 3.14^{2} * \mathrm{E}^{*} \mathrm{~A}\right) /(\mathrm{l} / \mathrm{k})^{2}$

here,

$\mathrm{C}=0.25$ (For column with one end fixed and other end free)

$$
\begin{aligned}
& \mathrm{E}=2 * 10^{5} \mathrm{~N} / \mathrm{mm}^{2} \\
& \mathrm{~A}=(3.14 / 4) *\left(\mathrm{do}^{2}-\mathrm{di}^{2}\right) \\
& \mathrm{l}=\text { Length of the column } \\
& \mathrm{k}=\left(\operatorname{sqrt}\left(\mathrm{do}^{2}+\mathrm{di}^{2}\right)\right) /(4) \\
& \mathrm{k}=\text { radius of gyration }
\end{aligned}
$$

Substituting the values and the standard pipe outer and inner diameter values are referred as $73 \mathrm{~mm}$ and $68 \mathrm{~mm}$ respectively.

$\mathrm{W}_{\mathrm{cr}}=3640 \mathrm{kgf}$

Safe load $=$ ultimate load/factor of safety

Here,

Factor of safety $=4$

Therefore, Safe load $=910 \mathrm{kgf}$

In this $1 \mathrm{KW}$ project work the load to be checked is $772.965 \mathrm{kgf}$ and $607 \mathrm{kgf}$ respectively.

This load is less than the design safe load. Therefore the design is safe.

\section{Deflection of column}

The deflection of column is given by,

$\mathrm{Ymax}=\left(\mathrm{PL}^{3}\right) /(3 \mathrm{EI})$

Where,

$\mathrm{P}=\mathrm{Load}$

$\mathrm{L}=$ Length of the column

$\mathrm{I}=$ Moment of inertia

Taking diameter values from 8 " pipe standards, we obtain outer and inner diameter as,

do $=219 \mathrm{~mm}$, di $=173 \mathrm{~mm}$

Substituting the values, we get,

Ymax $=0.41 \mathrm{~mm}$, which is less than the allowable deflection. Hence the design is safe.

4.4.2 Deflection of column due to bending

Bending stress is given by,

Bending stress, $\mathrm{Ib}=(\mathrm{Mb}) /($ Section modulus $)$

$\mathrm{Ib}=6.74 \mathrm{kgf} / \mathrm{mm}^{\wedge} 2$

This is less than allowable bending stress. Hence the design is safe.

\section{Channel Section}

Moment of inertia for channel section is given by, $\mathrm{I}=\left(\left(\mathrm{b} * \mathrm{~h}^{3}\right)-\left(\mathrm{b} 1 * \mathrm{~h} 1^{3}\right)\right) /(12)$

Where,

b, b1 =breadth of the flange $\mathrm{h}, \mathrm{h} 1 \mathrm{=}$ height of the flange As per standards, 
Table Dimensions of channel section

\begin{tabular}{|c|c|c|c|}
\hline B & B1 & H & H1 \\
\hline $25 \mathrm{~mm}$ & $20 \mathrm{~mm}$ & $220 \mathrm{~mm}$ & $210 \mathrm{~mm}$ \\
\hline
\end{tabular}

$\mathrm{I}=6748333 \mathrm{~mm}^{4}$

The deflection of the channel section is given as,

$\delta=\left(\mathrm{P} * \mathrm{~L}^{3}\right) /\left(48 * \mathrm{E}^{*} \mathrm{I}\right)$

where,

$\mathrm{P}=$ Load on the channel

L=Length of the channel

$\mathrm{E}=$ Young's modulus of the material

Sub to get,

$\delta=0.420977$

Deflection is very small and negligible.

\section{Cost Analysis}

The cost of the present solar tracking system is high with poor stability.Therefore, it is not used mostly for the renewable energy system for renewable power production.In this cost analysis, by using channel section give high stability with reduced material cost.Also by using worm gear in the solar tracking system,the actuator and braking cost of the system is reduced.

A channel of top and bottom flange dimensions is $5 \times 20$ x 994 .

The centre flange of dimension $200 \times 5 \times 994$

The volume of 1 channel material can be calculated as $1192800 \times 10^{-9} \mathrm{~m}^{3}$

Totally 24 channels are used,

$$
\begin{aligned}
& 24 \text { channels volume } \quad=0.0248 \mathrm{~m}^{3} \\
& \text { Density of stainless steel }=7820 \mathrm{~kg} / \mathrm{m}^{3} \\
& \text { Mass = volume } \mathrm{x} \text { density } \\
& =223.65 \mathrm{~kg} \\
& =23399280 \times 10^{-9} \mathrm{~m}^{3}
\end{aligned}
$$

$1 \mathrm{~kg}$ Stainless steel cost $\quad=$ Rs 1000

Therefore, Total material cost $=$ Rs 405600

Actual weight $\quad=411 \mathrm{~kg}$

Actual material cost $\quad=411000 \mathrm{Rs}$

$\%$ Material cost reduction $\quad=1.31 \%$

Net cost of actual system

PV array

Material cost

$=411000$

Gear drive

$=30000$

1HP motor

$=15500$

Actuator cost

$=28000$

Charge controller

$=26000$

Battery

Total

Net calculated cost

Pv array

Material cost

Gear drive

1HP motor

Charge controller

Battery

Total

$\%$ Overall cost reduction $=5.6 \%$
$=12000$

$=594100$

\section{CONCLUSION}

The worm gear drive is designed based on specific site condition live load and dead load.

The gear box and motor requirements for the worm drive to operate under wind load condition is estimated. The worm gear drive acts as a self-locking wheel which eliminates the cost of the actuator, braking system and also minimizes the dead load of the system. Channel section is used as a modified structure load carrying member which eliminates the material cost of the solar tracker about $2.39 \%$. Hence by using worm drive and channel section the overall cost of the system is reduced to about $6.7 \%$ and thereby the structural rigidity and stability of the solar tracking system is attained. Precise gearing of the system is designed which enhances the better performance of tracking accuracy.

\section{REFERENCES}

1. A Review on Solar Tracking System: A Technique of Solar Power Output Enhancement Jamilu Ya'u MuhammadMohammed Tajudeen JimohIbrahim Baba Kyarilbrahim Musa.

2. Advances in solar photovoltaic tracking systems: A review N. Al-Rousan, Nor Ashidi Mat Isa Mohd Khairunaz Mat Desa.

3. A design of single axis sun tracking system. Asmarashid Ponniran,Ammar Hashim ,Handy Ali Munir.

4. Design and Fabrication of single axis solar tracking system.Ashwin R, Joshuaraj Immanuel K, Lalith Sharavan C, Ravi Prasad P.S, Varun A.K

5. David A Rothery "An Introduction to the solar power".

6. Construction of Single Axis Automatic Solar Tracking System Md. Khalid Iqbal, Tanvir Islam, M. Chowdhury, Ahmed Imteaj.

7. Design and construction of an automatic solar tracking system ;Md. Tanvir Arafat Khan ; S.M. Shahrear Tanzil ; Rifat Rahman ; S M Shafiul Alam.

8. Design, Structural Analysis and Implementation of Photovoltaic Dual-Axis Solar Tracking System Mohammed. Ahmed, Syed Azam Pasha Quadri.

9. "solar tracking system: more efficient use of solar panels" by j. Rizk, and y. Chaiko.

10. Solar tracking systems: Technologies and trackers drive $\begin{array}{llll}\text { types } & - & \text { A } & \text { review }\end{array}$ A.Z.HafezabA.M.YousefacN.M.Haraga.

11. Concept of Mechanical Solar Tracking System Rohit Agarwal.

12. E Weise, R Klockner, R Kniel, Ma Sheng Hong, Qin Jian Ping, "Remote Power Supply using Wind and Solar energy- a Sino-German Technical Cooperation Project", Beijing International Conference on Wind Energy, Beijing 1995.

13. Guihua. Li., Runsheng Tang., and Hao Zhang. 2012. "Optical Performance Of Horizontal Single Axis tracked Solar Panels:2012." International Conference on Future Energy, Environment and materials 16:1744-1752.

14. C. Alexandru and N. I. Tatu, "Optimal design of the solar tracker used for a photovoltaic string," J. Renewable Sustainable Energy 5, 023133 (2013).

15. S. A. Sharaf Eldin, M. S. Abd-Elhady, and H. A. Kandil, "Feasibility of solar tracking systems for PV panels in hot and cold regions," Renewable Energy 85, 228-233 (2016).

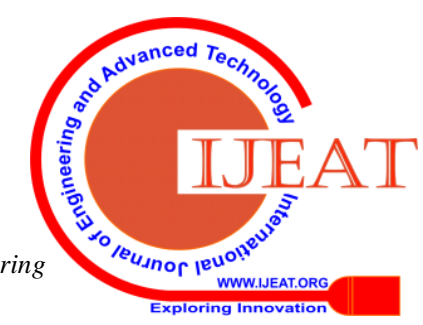




\section{AUTHORS PROFILE}

Billy D Master of Engineering in Solar Energy,AnnaUniversity,Chennai has published a technical paper on National Conference title "Automatic self-locking solar tapping system".

PaulmarPushparaj JMaster of Engineering in CAD,AnnaUniversity,Chennai has published a paper in national conference on Composite Materials.

Dr. M.VetrivelSezhianPh.Dhas published 3 National papers and 11 International papers and also presented 3 National and 5 International conference papers. 